\title{
Screening women with a personal history of breast cancer: overview of the evidence on breast imaging surveillance
}

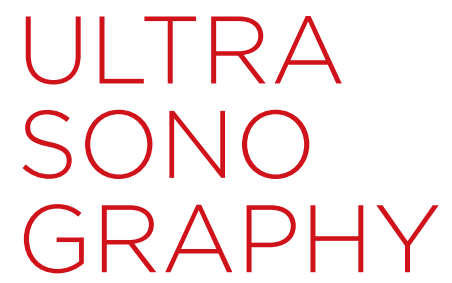

\author{
Nehmat Houssami ${ }^{1}$, Nariya $\mathrm{Cho}^{2}$ \\ ${ }^{1}$ Sydney School of Public Health, Sydney Medical School, University of Sydney, Sydney, \\ Australia; ' 2 Department of Radiology, Seoul National University Hospital, Seoul, Korea
}

\section{REVIEW ARTICLE}

https://doi.org/10.14366/usg. 18017 pISSN: 2288-5919 - eISSN: 2288-5943 Ultrasonography 2018;37:277-287

This work reviews the evidence on breast imaging for screening (surveillance) in women with a history of breast cancer (BC). Early detection of second BCs in these women improves their prognosis based on studies using mammography (usually with clinical examinations) for surveillance. Cohort studies have estimated that mammography surveillance has moderate sensitivity (65.4\%) and good specificity (98.3\%), and have shown that these women are at a higher risk of interval BC than age- and breast density-matched women without a history of BC. Studies of adjunct imaging (ultrasound, magnetic resonance imaging) for surveillance that have reported detection and accuracy measures have generally shown that adjunct imaging detected more second BCs than mammography and added substantially to the amount of false-positive results; however, little evidence exists regarding screening efficacy of adjunct imaging as part of routine surveillance.

Keywords: Breast neoplasms; Mammography; Mass screening

\section{Introduction}

From a global perspective, breast cancer (BC) is the most common cancer in females, with an estimated 2.4 million incident cases in 2015 [1]. Vast improvements in BC treatments, populationlevel early-detection strategies for $\mathrm{BC}$, and burgeoning longevity in countries with developed health systems have contributed to a growing population of women with a personal history of $B C$, also referred to as $B C$ survivors. Women with a personal history of $B C$ have a sustained long-term risk of experiencing another $B C$ diagnosis, which may be another primary $B C$ or an in-breast (local) recurrence in the treated conserved breast (an ipsilateral $B C$ ), or a contralateral $B C$ [2-4]; for simplicity, these may be collectively referred to as a second $B C$. The risk of developing a second $B C$ in either the treated or previously unaffected breast varies according to tumour-related and therapeutic factors associated with the first cancer. In general, women with early-stage invasive BC treated with breast conservation and adjuvant radiation, with long-term follow-up, are reported to develop ipsilateral $\mathrm{BC}$ at rates ranging from $0.4 \%$ to $1 \%$ per year [5-7]. A large population study by Gao et al. [8] reported contralateral $B C$ rates of $6.1 \%$ at 10 years and $12 \%$ at 20 years, which approximates an annualised rate of $0.6 \%$ for contralateral $\mathrm{BC}$ in women with a personal history of $\mathrm{BC}$. In a more

Received: April 6, 2018 Revised: May 29, 2018 Accepted: June 7, 2018

Correspondence to: Nehmat Houssami, MBBS, PhD, Sydney School of Public Health (A27), Sydney Medical School, University of Sydney, Sydney NSW 2006, Australia

Tel. +61-0419-273510

E-mail: nehmat.houssami@sydney. edu.au
This is an Open Access article distributed under the terms of the Creative Commons Attribution NonCommercial License (http://creativecommons.org/ licenses/by-nc/3.0/) which permits unrestricted noncommercial use, distribution, and reproduction in any medium, provided the original work is properly cited.

Copyright (C) 2018 Korean Society of Ultrasound in Medicine (KSUM)

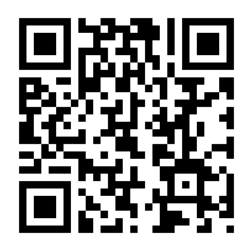

How to cite this article:

Houssami N, Cho N. Screening women with a personal history of breast cancer: overview of the evidence on breast imaging surveillance. Ultrasonography. 2018 0ct;37(4):277-287. 
recent study, Lee et al. [2] reported the cumulative risk of a second $\mathrm{BC}$ at 5 years, counting events in either breast, as 54 per 1,000 women, corresponding to a rate of approximately $1 \%$ per annum in cohorts with a history of stage $0-\|$ first BC. Hence, guidelines for the follow-up of women with a history of $B C$ recommend breast screening for the early detection of second $B C$ events; however, it should be noted that breast surveillance represents only one component amongst the various physical and psycho-social health needs that merit ongoing follow-up in women with a personal history of $B C[9-11]$.

This review summarizes the evidence on breast imaging for screening women with a personal history of BC. Imaging surveillance in this population supports the early detection and treatment of second $B C$ events, with potential benefits for the prognosis and quality of life in women who have already experienced $B C$.

\section{Is Breast Screening in Women with a Personal History of BC Effective?}

No randomised controlled trials (RCTs) have examined the effect of breast screening on $\mathrm{BC}$ mortality in women with a personal history of $B C$. Further, most of the evidence on the effects or efficacy of breast screening in women with a personal history of $B C$ relates to mammography, combined mammography and clinical examinations, or symptomatic versus asymptomatic detection in strategies that use mammography as the primary imaging modality [12]. The potential benefit of screening this special population of women has been based on an extrapolation of the likely benefit from RCTs of population-level mammography screening, complemented by evidence from observational studies [12-14]. Extrapolation of the benefits of population-level mammography screening trials to women with a personal history of $B C$ requires making substantial assumptions, since the early detection of second BCs may not confer the anticipated benefit if the risk of mortality in these women is determined by the first $B C$. This possibility would be expected to diminish the benefit of early detection of a second BC. However, a number of non-randomised studies have examined the impact of breast screening or early detection of second $\mathrm{BC}$, generally using mammography as the primary imaging modality, and these studies have provided evidence that earlier detection of second $B C s$, before symptoms have developed, is beneficial in women with a history of BC [12-14].

When the literature that specifically focuses on the detection of second $B C$ events is considered, excluding studies of in-breast recurrences occurring simultaneously with metastases, the evidence of benefit is frequently estimated as a hazard ratio (HR), and the reported HRs range broadly. The study-specific HRs for the detection of ipsilateral or contralateral $B C$ in women with a history of $B C$ range between 0.19 and 0.82 for early or asymptomatic detection, based on surveillance strategies that use mammography, relative to symptomatic or clinical detection [13,15-21]. This means that early or asymptomatic detection is associated with a beneficial effect in the range of an $18 \%$ to $81 \%$ relative reduction in the hazard of $B C$ death, relative to symptomatic or clinical detection of second BCs $[13,15-21]$. This broad range should be interpreted cautiously, due to the limitations of lead-time and length-time bias inherent in nonrandomised studies of cancer screening assessing survival, which could over-estimate the benefits.

A further methodological issue in this particular context is whether studies measure survival or follow-up time from the time of diagnosis of the first or the second $B C$ : measuring $B C$ survival from the first $B C$ helps minimise lead-time bias in estimating the effect of detection of the second cancer $[15,17]$. Estimates of the early detection of ipsilateral $B C$ or contralateral $B C$, however, are likely to be affected by length-time bias $[15,17]$, and this bias has only been specifically considered in a single study by Houssami et al. [15]. That study examined the effect of asymptomatic versus symptomatic detection of second $B C s$ in a cohort of 1,044 women with a history of $B C$ who received mammography surveillance and were diagnosed with second BCs [15]. It showed that asymptomatically-detected second $B C s$ were significantly associated with earlier detection and had a more favourable stage than symptomatic second $B C s$, as they were smaller and had fewer node metastases [15]. The HR for asymptomatic relative to symptomatic detection was 0.53 , allowing for lead-time bias by measuring disease-specific survival from the first $B C$; when this estimate was also adjusted for length-time bias, the HR ranged from 0.53 to 0.73 [15]. Buist et al. [13] reported on a cohort of 1,235 women aged 65 years or older with stage I-II BC who had received long-term follow-up, and showed that a modest reduction in $B C$-specific death $(H R, 0.82)$ was associated with receipt of surveillance mammography (vs. none) in the preceding year. These two studies most likely provide more robust results on the efficacy of surveillance mammography than some of the earlier studies that showed relatively large estimated benefits.

\section{Is Mammography Accurate?}

Although the evidence on screening efficacy in women with a history of $B C$, outlined above, is based on using mammography as the imaging modality for surveillance, several studies have reported that mammography has a modest detection capability in this population. The majority of studies of mammography in women with a history of $B C$ have reported the proportion of second $B C s$ detected by mammography (which may be the equivalent of sensitivity, 
depending on the methods used and whether there was follow-up to identify missed cancers), but few studies have reported interval cancer data in this setting, which limits information on sensitivity, and few studies have reported the specificity of surveillance. Studies generally have reported the proportion of ipsilateral $B C s$ detected by mammography to range between $50 \%$ and $80 \%[6,15,22-28]$ if any detection by mammography is counted in the analysis. Given that data from screening mammography and clinical examination are often reported jointly, this should be distinguished from the proportion of "mammography-only" detected ipsilateral BCs, which is usually lower than the above-reported range, typically in the range of $10 \%-51 \%[6,21,22,25,27-34]$. As an example, van der Sangen et al. [35] reported that $51 \%$ of ipsilateral BCs were detected by clinical examination with or without mammography, while $38 \%$ were detected by mammography alone.

Published estimates of the proportion of contralateral BCs detected through mammography surveillance in women with a personal history of $B C$ range from $45 \%$ to $90 \%[6,15,31,33,36-$ 38]. Lu et al. [38] reported estimates of programme sensitivity and specificity for surveillance mammography. A sensitivity of $59.6 \%$ was shown for the detection of contralateral $B C$, while in women who complied with annual mammography, it increased to $70.8 \%$; the specificity of mammography was high, at $98.3 \%$. This study also found that $34 \%$ of contralateral BCs in women with a personal history of $\mathrm{BC}$ were diagnosed as interval cancers [38].

Large cohort studies of women with a personal history of $B C$ have been reported in relatively recent years from the Breast Cancer Surveillance Consortium [39], providing major insights into the accuracy of screening mammography in these women. One of these studies examined screening mammograms from 19,078 women with a history of stage I-II BC who received follow-up to identify second $B C$, including interval cancers [39]. This study matched 58,870 screens in women with a history of $B C$ by age-group and breast density to 58,870 screens in women without a history of $B C$, thereby providing robust comparative data on screening outcomes. The $B C$ detection rate was significantly higher in women with a history of $B C$ than in women without a history of $B C$ ( 6.8 vs. 4.4 per 1,000 screens, respectively), as was the interval $B C$ rate (3.6 vs. 1.4 per 1,000 screens, respectively). Furthermore, screening sensitivity was significantly lower in women with a history of $B C$ than in women without such a history (65.4\% vs. $76.5 \%$, respectively), as was specificity $(98.3 \%$ vs. $99.0 \%)$. In women with a history of BC, the sensitivity of mammography was lower in the initial 5 years after the first BC treatment $(60.2 \%)$ than afterwards $(70.8 \%)$, and was similar for detection of ipsilateral BC (66.3\%) and contralateral BC (66.1\%).

Subsequent studies $[2,40]$, also conducted within the Breast
Cancer Surveillance Consortium, aimed to identify risk factors for interval second BCs after surveillance mammography in women with a history of BC. One of these studies, reported by Houssami et al. [40], was based on 67,819 screening mammograms in women with a history of $B C$. It identified age $<40$ years at the first $B C$ diagnosis, extremely dense breasts, and treatment with breast conservation without radiation as significant predictors of an interval invasive $B C$ within 1 year of negative mammography [40]. Since the majority of in-breast recurrences occur within 5 years of treatment, Lee et al. [2] estimated the 5 -year risk of an interval invasive second $B C$ amongst a cohort of 15,114 women with a history of stage $0-\| \mathrm{BC}$, and showed that four variables were significant independent predictors of interval $B C$ risk: first $B C$ grade, the mode of detection of the first $B C$ (whether screening-detected or an interval $B C$ ), treatment with breast conservation without radiation, and heterogeneously dense breasts on mammography. Knowledge of the risk factors for interval (second) BCs in women with a history of BC following negative surveillance mammography can guide recommendations on the potential use of adjunct imaging in this setting.

It should be noted that many of the studies of mammography in women with a history of $B C$ used relatively old technology. An overview by Montgomery et al. [41] suggested a temporal increase across surveillance studies in the proportion of second BCs that are detected through mammography, as did a study from Tuscany that showed that the proportion of second BCs detected through mammography increased significantly over time, almost doubling from $33 \%$ to $60 \%$ [15]. Lu et al. [38] found a significant trend in which contralateral $B C$ was more likely to be detected by mammography surveillance in women who had their first $B C$ diagnosed after 1994 relative to the earlier time period $(P=0.005)$. Presumably, this relates to improvements in mammography technology or possibly improved uptake of surveillance. Thus, it is important to acknowledge that some of the evidence summarised in this review, and in earlier reviews of this topic $[41,42]$, may not reflect the detection capability of digital mammography screening of women with a history of $\mathrm{BC}$. This possibility underscores the need for new studies using digital mammography platforms, particularly tomosynthesis.

\section{Digital Breast Tomosynthesis}

The evidence on digital breast tomosynthesis (DBT) for populationlevel screening has evolved rapidly in recent years, as DBT screening has been shown to improve $B C$ detection rates and/or to reduce recall rates (compared to mammography), with some variability in the evidence related to the screening context [43]. However, there are very few data on the application of DBT for screening women with a history of BC. One study of DBT in the surveillance setting, 
based on 618 women with a history of $B C$, showed that the addition of DBT to digital mammography reduced the rate of indeterminate results from $13.1 \%$ to $10.5 \%(P=0.018)$ [44]. Given the evidence on DBT from population screening studies, research on the use of DBT to screen women with a history of $B C$ would make a valuable contribution to breast surveillance practice.

\section{Which Breast Imaging Modalities Are Recommended in Surveillance Guidelines?}

A review of guideline recommendations on breast imaging surveillance in women with a history of BC (summarised in Table 1) shows that they consistently recommend mammography as the primary modality. This is not surprising, since breast screening efficacy in women with a history of $B C$ is established on the basis of mammography, as described earlier in this review. In contrast, recommendations for adjunct breast imaging, ultrasound, and magnetic resonance imaging (MRI) in this setting vary considerably, as shown in Table 1. To place this in context, the evidence on adjunct imaging in women with a history of BC will be summarized and discussed next.

\section{Adjunct Imaging for Breast Surveillance}

\section{Breast Ultrasound}

In breast imaging practice, ultrasound is a key modality for investigating women with symptoms or screen-detected findings. Although generally not recommended for routine surveillance in women with a history of $B C$ (as indicated earlier in this review, only 1 guideline [45] recommends ultrasound) (Table 1), its use as an adjunct to mammography is not uncommon, especially in women with dense breasts. However, there are no data on how often ultrasound is used in the surveillance setting. The application of ultrasound to screen women with dense breasts on mammography is based on evidence of incremental (additional) BC detection using ultrasound after "negative" mammography in women with dense breasts $[46,47]$. However, the majority of studies of ultrasound screening in women with dense breasts on mammography either do not include women with a history of $B C$, or include only a small proportion of such women [46]. An exception to these studies is a prospective study of women with dense breasts by Berg et al. [48] in which around $54 \%$ of participants also had a history of BC; that study evaluated the combination of mammography and hand-held ultrasound compared to mammography alone in women with dense breasts and additional risk factors that placed them at a moderately increased risk of $B C$, and reported results for the subgroup of women with a history of $B C$. The cancer detection rate for mammography alone was 8.2 per 1,000 screens, whereas combining mammography with ultrasound detected an additional 4.3 cancers per 1,000 screens. It should be noted that ultrasound alone did not have better detection ( $B C$ detection rate, 8.7 per 1,000 screens) than mammography alone, but the combination significantly increased the cancer detection rate (BC detection, 12.5 per 1,000 screens) in women with a history of BC. Adding ultrasound to mammography in the surveillance setting, however, increased the burden of unnecessary recall and biopsy, increasing recall by $8.6 \%$, the biopsy rate by $4.7 \%$, and recommendations for short-term review by $5.2 \%$ [48], at minimum doubling these outcomes.

A retrospective study from a Korean centre, reported by Suh et al. [49], that used mammography and ultrasound for surveillance of

Table 1. Guideline recommendations on breast imaging surveillance in women with a personal history of breast cancer

\begin{tabular}{|c|c|c|c|}
\hline Guideline & Mammography & Ultrasound & MRI \\
\hline $\begin{array}{l}\text { Chinese Anti-Cancer Association (Breast Cancer } \\
\text { Committee) [50] }\end{array}$ & Annual mammography & Not specified & Not recommended \\
\hline $\begin{array}{l}\text { American Cancer Society/American Society of } \\
\text { Clinical Oncology, } 2016 \text { [9] }\end{array}$ & Annual mammography & Not specified & $\begin{array}{l}\text { Recommends against routine MRI unless } \\
\text { the patient meets high-risk criteriaa) }\end{array}$ \\
\hline $\begin{array}{l}\text { National Comprehensive Cancer Network (NCCN), } \\
2016 \text { [11] }\end{array}$ & Annual mammography & Not specified & Not specified \\
\hline $\begin{array}{l}\text { European Society for Medical Oncology (ESMO), } \\
2015 \text { [45] }\end{array}$ & Annual mammography & Annual ultrasound & $\begin{array}{c}\text { May be used (young patients with dense } \\
\text { breasts and genetic history) }\end{array}$ \\
\hline $\begin{array}{l}\text { National Institute for Health and Care Excellence } \\
\text { (NICE), } 2014 \text { [51] }\end{array}$ & Annual mammography & Not recommended & Not recommended \\
\hline American College of Radiology (ACR), 2014 [52] & Annual mammography & $\begin{array}{l}\text { Based on risk assessment } \\
\text { (if MRI is contraindicated) }\end{array}$ & Based on risk assessment \\
\hline $\begin{array}{l}\text { American Society of Clinical Oncology (ASCO), } \\
2013 \text { [10] }\end{array}$ & Annual mammography & Not specified & Not recommended \\
\hline
\end{tabular}

MRI, magnetic resonance imaging.

${ }^{a}$ High-risk (>20\% lifetime risk of second cancer). 
women with a history of $\mathrm{BC}$, highlighted the capability of ultrasound to detect $B C$ recurrences not detected on mammography. However, in many instances these cases were in regions not accessible to mammography, such as the axilla or the mastectomy bed. In that study, ultrasound detected most second BCs in the contralateral breast of women who had received mastectomy (sensitivity, 95\%), but had limited sensitivity for ipsilateral cancers in women who had breast conservation (sensitivity, 43\%), and detection was at the trade-off of many false-positive findings [49]. In practice, false positives on ultrasound can be promptly addressed with ultrasoundguided needle biopsy, but they nonetheless add to the burden of screening-related interventions in this population of women. Further, it can be hypothesised that the integration of elastography into ultrasound practice may potentially reduce ultrasound-related false positives in the breast surveillance setting, but that remains to be demonstrated.

A key study of adjunct surveillance imaging was reported recently by Cho et al. [44], who undertook a prospective multi-centre trial in Korea, directly comparing ultrasound and MRI with mammography surveillance in a well-defined cohort of 754 women with a history of breast-conserving therapy. The trial focused on women whose initial $B C$ was diagnosed at age $\leq 50$ years, a group in whom mammography has been shown to have suboptimal sensitivity in women with a history of BC [39]. The study findings, which are summarised in Table 2, showed that ultrasound and MRI each yielded additional BC detection (not detected on mammography) in these women. It can be seen from the data in Table 2 that the detection capability of ultrasound is intermediate between mammography and MRI, and that each adjunct modality imposes a substantial recall and biopsy proportion compared to screening with mammography alone.

\section{Clinical Aspects of Breast Ultrasound in the Surveillance Setting}

Although there is no robust evidence to support routine implementation, ultrasound screening has been widely used in imaging practice to screen women with a history of $B C$ in some Asian countries, particularly in Korea [49,53-55] (Table 3). Several retrospective studies have reported $B C$ detection rates between 6.4 and 21 per 1,000 examinations in women with a history of BC [49, 53-55] (Table 3). However, these studies did not consistently clarify which modality contributed to cancer detection: mammography, ultrasound, clinical breast examination, or a combination thereof.

A recent study by Song et al. [56] reported the performance of ultrasound surveillance, including standardized monitoring parameters, amongst 6,584 women with a personal history of $B C$ who had negative mammography results. They found an additional cancer detection rate of 2.88 per 1,000, and reported the following estimates: interval cancer rate, 1.50 per 1,000; sensitivity, $67.9 \%$; specificity, 91.2\%; abnormal interpretation rate, $9.1 \%$; and positive predictive value (PPV) for biopsy (PPV $\left.{ }_{3}\right), 22.6 \%$. In addition, $79.0 \%$ (15 of 19) of the detected cancers were stage 0 or I. Based on the reported interval cancer rate $(1.50 / 1,000)$, ultrasound surveillance might not fully overcome the sensitivity limitation of mammography. Regarding the disadvantages of ultrasound surveillance, the abnormal interpretation rate was $9.1 \%(596$ of 6,584$)$ and the PPV for recall $\left(\mathrm{PPV}_{1}\right)$ was $1.7 \%$ (22 of 1,278); the abnormal interpretation rate is similar to that of $10.6 \%$ reported for screening mammography by the Breast Cancer Surveillance Consortium [57]. The relatively low PPV , was caused by a high proportion of Breast Imaging Reporting and Data System category 3 lesions (which had no cancer detection yield) on ultrasound screens in this study. Thus, the low PPV 1 of ultrasound screening might be improved

Table 2. Direct comparison of surveillance modalities in 754 women (2,065 screens) with a history of breast-conserving therapy at age $\leq 50$ years (Cho et al.) [44]

\begin{tabular}{lcll}
\hline \multicolumn{1}{c}{ Detection or accuracy metric } & Mammography & \multicolumn{1}{c}{ Ultrasound } & \multicolumn{1}{c}{ MRI } \\
\hline Cancer detection rate per 1,000 screens & 4.4 & Stand-alone 5.3 & Stand-alone 7.3 \\
& & Adjunct $6.8(P=0.03)^{a)}$ & Adjunct $8.2(P=0.003)^{a)}$ \\
Sensitivity & $53 \%$ & Stand-alone $65 \%$ & Stand-alone $88 \%$ \\
& & Adjunct $82 \%(P=0.07)^{\mathrm{a})}$ & Adjunct 100\% $(\mathrm{P}=0.01)^{\mathrm{a})}$ \\
Specificity) & $96 \%$ & Stand-alone $90 \%$ & Stand-alone $90 \%$ \\
& & Adjunct $88 \%(\mathrm{P}=0.001)^{\mathrm{a})}$ & Adjunct $87 \%(\mathrm{P}=0.001)^{\mathrm{a})}$ \\
Recall rate & $4.4 \%$ & $10.1 \%$ & $10.7 \%$ \\
Biopsy rate & $0.5 \%$ & $1.1 \%$ & $2.5 \%$ \\
\hline
\end{tabular}

MRI, magnetic resonance imaging.

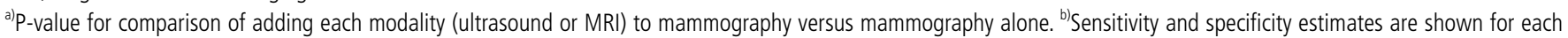
modality as stand-alone and for the combination of each modality (ultrasound or MRI) with mammography versus mammography alone. 
by reclassifying category 3 lesions as category 2 lesions to avoid unnecessary recall.

Given the potential to reduce abnormal interpretations of ultrasound, the easy applicability of ultrasonography in screening and its tolerability for women, the absence of ionizing radiation and contrast agents, and the availability of ultrasound-guided biopsy to resolve the status of detected lesions, ultrasound surveillance remains a practical supplement to mammography in women with a personal history of breast cancer.
Illustrative examples of true-positive and false-positive detection using ultrasound in the surveillance setting are shown in Figs. 1 and 2 , respectively.

\section{MRI of the Breast}

There are two sources of evidence on breast MRI in women with a history of BC that provide data on detection capability or accuracy, but no studies have been conducted of MRI screening efficacy in the surveillance setting. Studies of breast MRI in women at a high risk of

Table 3. Studies of US screening in women with a personal history of BC

\begin{tabular}{|c|c|c|c|c|c|}
\hline Study & Study design ${ }^{a)}$ & $\begin{array}{c}\text { Recall or } \\
\text { abnormal US }\end{array}$ & $\begin{array}{l}\text { US-related } \\
\text { biopsy }\end{array}$ & $\begin{array}{l}\text { No. of detected } \\
\text { BCs }\end{array}$ & $\begin{array}{l}\text { Cancer detection rate } \\
\text { per } 1,000 \text { screens }\end{array}$ \\
\hline Kim et al., 2010 [53] & $\begin{array}{l}\text { Retrospective study of records of women with a } \\
\text { history of } B C(874,1,796)\end{array}$ & NR & NR & 15 & 8 \\
\hline Lee et al., 2013 [55] & $\begin{array}{l}\text { Retrospective study of records of women with a } \\
\text { history of } B C(468,1,180)\end{array}$ & $82 / 468$ (17.5\%) & 19/468 (4.1\%) & 10 & 21 \\
\hline Song et al., 2018 [56] & $\begin{array}{l}\text { Retrospective study of database of women with } \\
\text { a history of } B C(6,584,6,584) \text { compared with } \\
\text { those in women without a history of BC }\end{array}$ & $596 / 6,584$ (9.1\%) & $181 / 6,584(2.7 \%)$ & 19 & 2.88 \\
\hline
\end{tabular}

US, ultrasonography; BC, breast cancer; NR, not reported.

${ }^{a}$ Numbers in parentheses indicate number of women and exams.

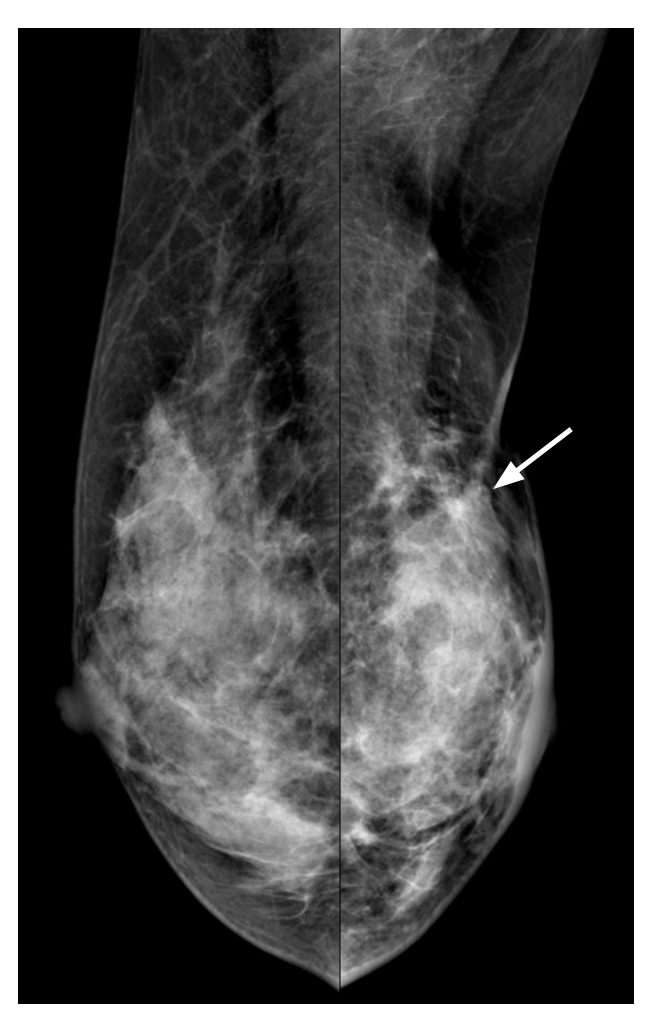

A

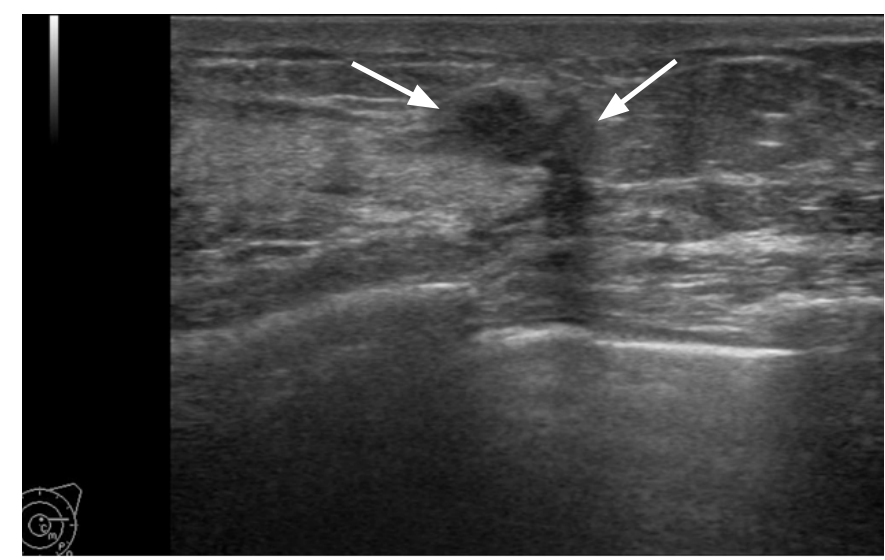

B

Fig. 1. True-positive screening breast ultrasound in a 49-year-old woman with a personal history of breast cancer, who had breast-conserving surgery 12 months prior to the surveillance imaging shown.

Surgical histopathology of the initial cancer revealed a $2.5-\mathrm{cm}$ high-grade ductal carcinoma in situ (DCIS) with negative resection margins. She also received radiation therapy following surgery. A. Mammography shows a postoperative deformity without a specific abnormality (arrow) in the left upper outer breast. B. Ultrasonography shows an irregular hypoechoic mass (arrows) near the postoperative scar in the 2-o'clock position, which was confirmed to be a $2.2-\mathrm{cm}$ high-grade DCIS on surgical histology following total mastectomy. 


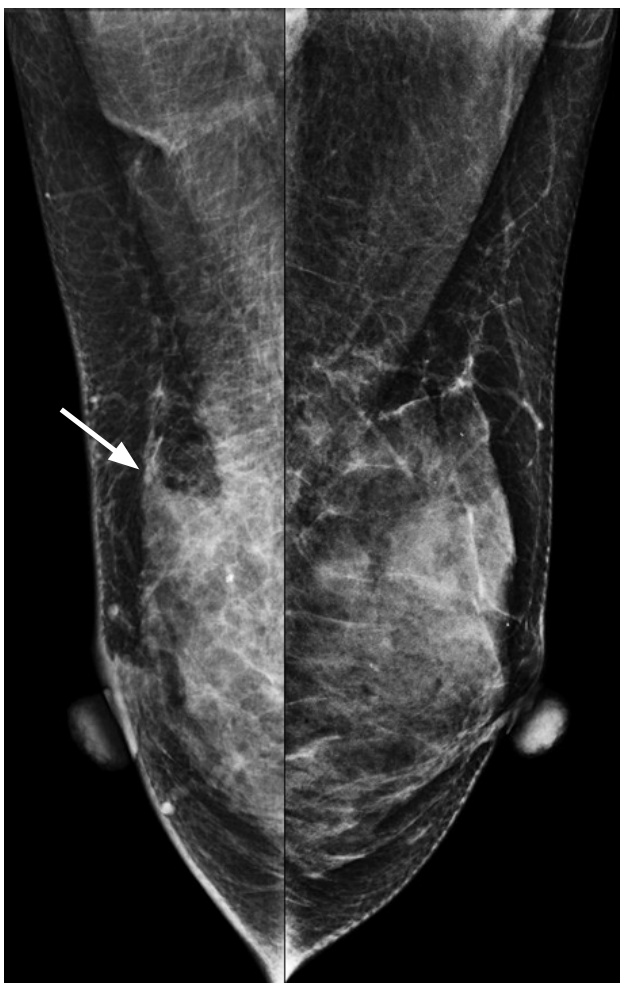

A

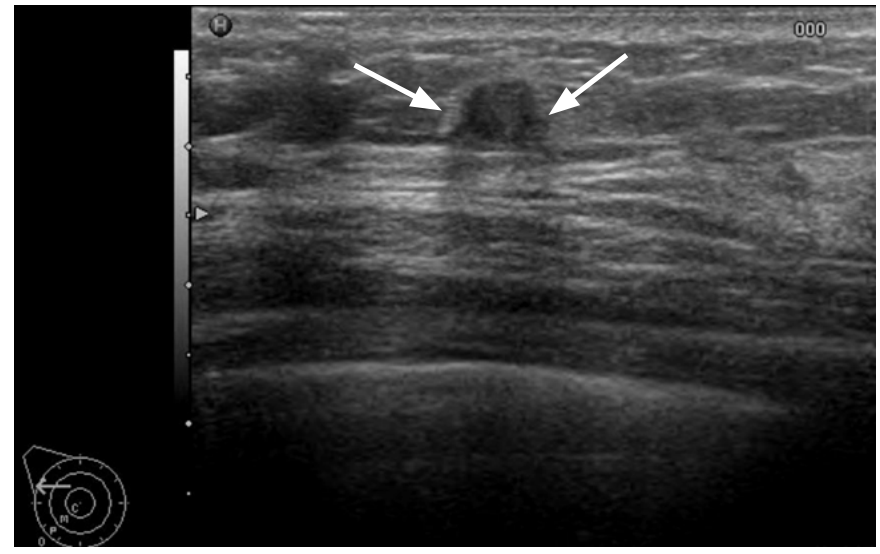

B

Fig. 2. False-positive screening breast ultrasound examination in a 38-year-old woman with a personal history of breast cancer.

Previously, she had undergone breast-conserving surgery. Surgical histopathology of the initial cancer revealed a $0.8-\mathrm{cm}$ invasive ductal carcinoma without axillary lymph node metastasis. A. Mammography shows a postoperative deformity without an abnormality (arrow) in the right upper outer breast. B. Ultrasonography shows a $0.7-\mathrm{cm}$ irregular hypoechoic mass (arrows) in the 10-o'clock position, which was confirmed as fat necrosis by ultrasound-guided core needle biopsy. On 58-month follow-up imaging, including ultrasound, there was no recurrent cancer.
$B C$ due to $B R C A 1$ or $B R C A 2$ mutations provide relevant information. A meta-analysis of 1,951 women with BRCA1/2 mutations from six prospective MRI screening studies, which included 345 women with a personal history of breast or ovarian cancer [58], showed that MRI had higher sensitivity than mammography $(85.3 \%$ vs. $39.6 \%$, $\mathrm{P}<0.001)$, although MRI had lower specificity than mammography $(84.7 \%$ vs. $93.6 \%, P=0.01)$. The current evidence on breast MRI surveillance in women with a history of (sporadic) BC comes from relatively small, retrospective studies of women who underwent $M R I$, and these studies generally suffer from both selection bias and lack of comparative data. The results of studies focusing on MRI screening in women with a history of $B C$ are shown in Table 4. The broad range of $B C$ detection rates (range, 9.9 to 39.4 per 1,000 screens) (Table 4) may be attributed to the differential selection of women for MRI surveillance, the predominance of prevalent screens in some studies, and the inclusion of women with additional risk factors for $B C$ in some studies, all of which can increase the underlying $B C$ rates and detection rates. The consequence of selection bias is that those selected for MRI surveillance in different practices may not represent the majority of women with a history of $B C$, who receive mammography without being further selected for $M R I$, so the results of these studies may not be generalizable to the broader population of women with a personal history of BC. Table 4 also shows heterogeneity in the reported data on recall and biopsy rates, although not all studies provided these data; the abnormal interpretation rate for MRI was in the range of $10.7 \%$ to $19.4 \%$ (Table 4).

Only one prospective trial of adjunct imaging has directly compared MRI and ultrasound with mammography across several surveillance rounds in a cohort of women with a history of BC. This study, by Cho et al. [44], is discussed in the ultrasound section of this review (Table 2), and used better methodology than the studies summarized in Table 4. Notably, although Cho et al. [44] showed a significantly higher $B C$ detection rate for MRI (combined with mammography) than for mammography alone (8.2 vs. 4.4 per 1,000 screens, respectively), it is clear that the estimated MRI detection rate in this study is below the above-described range for MRI studies shown in Table 4, most likely because Cho et al. [44] included a representative (unselected) cohort of women with a history of $B C$ in the trial.

\section{Conclusion}

Evidence that early detection of second $B C s$ in women with a personal history of $B C$ improves prognosis comes from studies that used mammography (usually with clinical examinations) as the main surveillance strategy. Well-executed cohort studies have estimated that mammography screening in this population of patients has 
moderate sensitivity (65.4\%) and good specificity (98.3\%), and have also shown that women with a history of $\mathrm{BC}$ are at a higher risk of experiencing an interval $\mathrm{BC}$ following screening mammography than age and breast density-matched cohorts without such a history. The latter finding is likely due to the higher underlying risk of $B C$ and the lower sensitivity of mammography in women with a history of
$B C$. Knowledge of the risk factors for interval cancers after negative surveillance mammography in women with a history of BC has evolved considerably, and we now have evidence on patient-related factors (e.g., young age) and first BC tumour- and/or treatmentrelated factors (e.g., receipt of breast conservation without radiation) that contribute to interval $\mathrm{BC}$ risk.

Table 4. Studies of MRI screening in women with a personal history of BC

\begin{tabular}{|c|c|c|c|c|c|}
\hline Study & Study designa) & $\begin{array}{l}\text { Recall or abnormal } \\
\text { MRI (\%) }\end{array}$ & $\begin{array}{c}\text { MRI-related } \\
\text { biopsy (\%) }\end{array}$ & $\begin{array}{l}\text { No. of MRI- } \\
\text { detected BCs }\end{array}$ & $\begin{array}{l}\text { Cancer detection rate } \\
\text { per } 1,000 \text { screens }\end{array}$ \\
\hline Elmore et al. [59] & $\begin{array}{l}\text { Retrospective review of records of women with a } \\
\text { history of } B C \text { who had an MRI screen }\left(141^{\text {b) }}\right)\end{array}$ & 11.3 & 4 & 2 & 9.9 \\
\hline Brennan et al. [60] & $\begin{array}{l}\text { Retrospective review of MRI examinations in } \\
\text { women with a history of } B C(144)\end{array}$ & NR & 31 & 17 (5 DCIS) & $11.8^{c)}$ \\
\hline Schacht et al. [61] & $\begin{array}{l}\text { Retrospective review of MRI examinations in } \\
\text { women with a history of } \mathrm{BC}(208)\end{array}$ & NR & NR & $6(2 \mathrm{DCIS})$ & $28.8^{c)}$ \\
\hline Gweon et al. [62] & $\begin{array}{l}\text { Retrospective study of records of women with a } \\
\text { history of BC who had negative mammography, } \\
\text { ultrasound, and also had MRI (607) }\end{array}$ & $19.3^{\mathrm{d})}$ & NR & $11(3 \mathrm{DCIS})^{\mathrm{d})}$ & $18.1^{d)}$ \\
\hline Giess et al. [63] & $\begin{array}{l}\text { Retrospective review of database of MRI } \\
\text { examinations to identify women with a history of } \\
\text { BC who had MRI }\left(691^{\text {b) }}\right)\end{array}$ & 10.7 & 5.6 & 12 & 10.1 \\
\hline Weinstock et al. [64] & $\begin{array}{l}\text { Retrospective review of MRI database to identify } \\
\text { women with a history of BC who had MRI (249) }\end{array}$ & NR & 10.8 & 11 (2 DCIS) & 19.3 \\
\hline Destounis et al. [65] & $\begin{array}{l}\text { Retrospective review of MRI examinations in } \\
\text { women with a personal history of pre-menopausal } \\
\mathrm{BC}\left(131^{\mathrm{b})}\right)\end{array}$ & 19.4 & 13.7 & 15 (4 DCIS) & 39.4 \\
\hline Lehman et al. [66] & $\begin{array}{l}\text { Retrospective review of MRI database to identify } \\
\text { women with a history of BC who had MRI (915) }\end{array}$ & 14.3 & 7 & 18 (4 DCIS) & 19.7 \\
\hline
\end{tabular}

$\mathrm{MRI}$, magnetic resonance imaging; $\mathrm{BC}$, breast cancer; NR, not reported; DCIS, ductal carcinoma in situ.

${ }^{a)}$ Numbers in parentheses indicate number of women. ${ }^{b}$ Denotes studies including women with additional risk (family history or gene mutations). ${ }^{\circ} \mathrm{Calculated}$ per 1,000

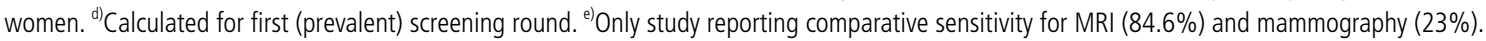

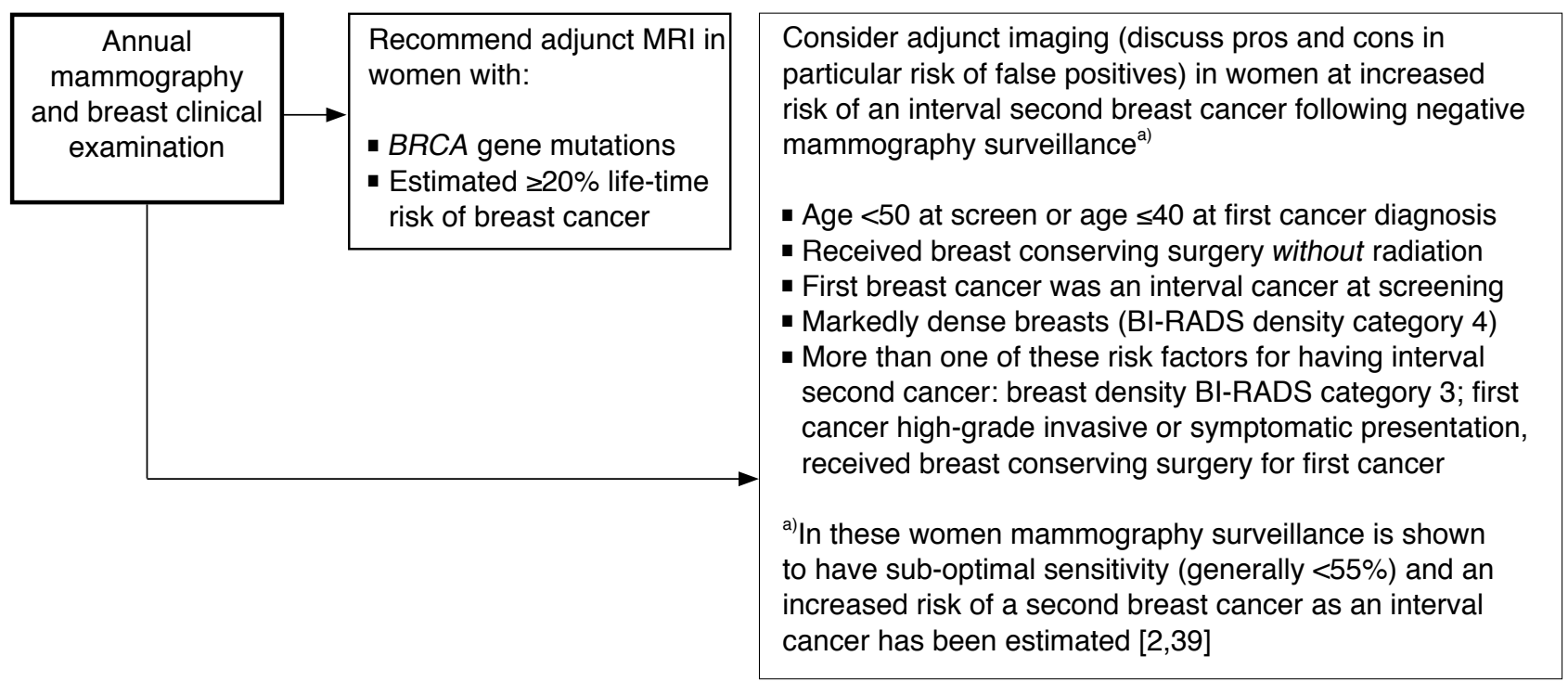

Fig. 3. A framework for breast imaging surveillance in women with a personal history of breast cancer. MRI, magnetic resonance imaging; BI-RADS, Breast Imaging Reporting and Data System. 
Studies that have examined adjunct imaging surveillance of women with a history of $B C$, primarily ultrasound or MRI, report on detection or accuracy measures, hence there is limited knowledge on the efficacy of adding these imaging tests as part of routine breast surveillance. These studies show that using adjunct imaging detects more second BCS (MRI more so than ultrasound) but also add substantially to the burden of recall and false-positive screening. Although MRI has higher additional detection yield than ultrasound in the surveillance setting, choice of adjunct imaging needs to consider access, cost and local imaging expertise ultrasound may be more feasible and is generally more available and more acceptable to women than MRI. Regardless of which adjunct imaging test is used, women should be informed about the additional risk of false-positives. Drawing on the evidence outlined in this review, a framework is shown in Fig. 3 to inform screening in women with a personal history of $\mathrm{BC}$.

\section{Future Research}

Studies comparing digital mammography with DBT screening in women with a history of $B C$ merit research effort, and could provide much-needed evidence in the surveillance setting. This can be expedited by large national or international collaborations to ensure sufficiently large datasets of second BC events; hence, collaborative DBT screening studies in women with a history of $B C$ should be a research priority. A future transition to DBT would require new studies comparing additional detection from ultrasound or MRI in women with a personal history of $\mathrm{BC}$ who receive $\mathrm{DBT}$ surveillance. Because of the heterogeneity in the risk of developing an interval $B C$ following mammography screening, risk models or calculators that reliably identify women with a history of $B C$ who are at a higher risk of interval $B C$ (following negative mammography) would be valuable, and could help tailor screening and support discussion of the advantages and disadvantages of adjunct imaging for breast surveillance.

ORCID: Nehmat Houssami: http://orcid.org/0000-0002-3641-952X; Nariya Cho: http://orcid.org/0000-0003-4290-2777

\section{Conflict of Interest}

No potential conflict of interest relevant to this article was reported.

\section{Acknowledgments}

N. Houssami receives research support through a National Breast Cancer Foundation (NBCF, Australia) Breast Cancer Research Leadership Fellowship.

\section{References}

1. Global Burden of Disease Cancer Collaboration, Fitzmaurice C, Allen C, Barber RM, Barregard L, Bhutta ZA, et al. Global, regional, and national cancer incidence, mortality, years of life lost, years lived with disability, and disability-adjusted life-years for 32 cancer groups, 1990 to 2015: a systematic analysis for the global burden of disease study. JAMA Oncol 2017;3:524-548.

2. Lee JM, Buist DS, Houssami N, Dowling EC, Halpern EF, Gazelle GS, et al. Five-year risk of interval-invasive second breast cancer. J Natl Cancer Inst 2015; 107:djv109.

3. Pan H, Gray R, Braybrooke J, Davies C, Taylor C, McGale P, et al. 20-Year risks of breast-cancer recurrence after stopping endocrine therapy at 5 years. N Engl J Med 2017;377:1836-1846.

4. Ciatto S, Houssami N, Martinelli F, Bonardi R, Cafferty FH, Duffy SW. Second breast cancers in a Tuscan case series: characteristics, prognosis, and predictors of survival. Br I Cancer 2008;99:539-544.

5. Kreike B, Hart AA, van de Velde T, Borger J, Peterse H, Rutgers $E$, et al. Continuing risk of ipsilateral breast relapse after breastconserving therapy at long-term follow-up. Int J Radiat Oncol Biol Phys 2008;71:1014-1021.

6. Montgomery DA, Krupa K, Jack WJ, Kerr GR, Kunkler IH, Thomas $J$, et al. Changing pattern of the detection of locoregional relapse in breast cancer: the Edinburgh experience. $\mathrm{Br} J$ Cancer 2007;96:1802-1807.

7. Voogd AC, Nielsen M, Peterse JL, Blichert-Toft M, Bartelink $H$, Overgaard $\mathrm{M}$, et al. Differences in risk factors for local and distant recurrence after breast-conserving therapy or mastectomy for stage I and II breast cancer: pooled results of two large European randomized trials. J Clin Oncol 2001;19:1688-1697.

8. Gao X, Fisher SG, Emami B. Risk of second primary cancer in the contralateral breast in women treated for early-stage breast cancer: a population-based study. Int I Radiat Oncol Biol Phys 2003;56:1038-1045.

9. Runowicz CD, Leach CR, Henry NL, Henry KS, Mackey HT, CowensAlvarado RL, et al. American Cancer Society/American Society of Clinical Oncology Breast Cancer Survivorship Care Guideline. CA Cancer J Clin 2016;66:43-73.

10. Khatcheressian JL, Hurley P, Bantug E, Esserman LJ, Grunfeld E, Halberg F, et al. Breast cancer follow-up and management after primary treatment: American Society of Clinical Oncology clinical practice guideline update. J Clin Oncol 2013;31:961-965.

11. National Comprehensive Cancer Network. Clinical practice guidelines in oncology: breast cancer, version 2, 2016 [Internet]. Fort Washington, PA: National Comprehensive Cancer Network, 2016 [cited 2017 Dec 15]. Available from: https://www.nccn.org.

12. Houssami N, Ciatto S. Mammographic surveillance in women with a personal history of breast cancer: how accurate? How effective? Breast 2010;19:439-445. 
13. Buist DS, Bosco JL, Silliman RA, Gold HT, Field T, Yood MU, et al. Long-term surveillance mammography and mortality in older women with a history of early stage invasive breast cancer. Breast Cancer Res Treat 2013;142:153-163.

14. Lash TL, Fox MP, Buist DS, Wei F, Field TS, Frost FJ, et al. Mammography surveillance and mortality in older breast cancer survivors. J Clin Oncol 2007;25:3001-3006.

15. Houssami N, Ciatto S, Martinelli F, Bonardi R, Duffy SW. Early detection of second breast cancers improves prognosis in breast cancer survivors. Ann Oncol 2009;20:1505-1510.

16. Schootman M, Fuortes L, Aft R. Prognosis of metachronous contralateral breast cancer according to stage at diagnosis: the importance of early detection. Breast Cancer Res Treat 2006;99:91-95.

17. Ciatto S, Miccinesi G, Zappa M. Prognostic impact of the early detection of metachronous contralateral breast cancer. Eur J Cancer 2004;40:1496-1501.

18. Doyle T, Schultz DJ, Peters C, Harris E, Solin LJ. Long-term results of local recurrence after breast conservation treatment for invasive breast cancer. Int J Radiat Oncol Biol Phys 2001;51:74-80.

19. Kaas R, Hart AA, Besnard AP, Peterse JL, Rutgers EJ. Impact of mammographic interval on stage and survival after the diagnosis of contralateral breast cancer. Br J Surg 2001;88:123-127.

20. Orel SG, Fowble BL, Solin LJ, Schultz DJ, Conant EF, Troupin RH. Breast cancer recurrence after lumpectomy and radiation therapy for early-stage disease: prognostic significance of detection method. Radiology 1993;188:189-194.

21. Voogd AC, van Tienhoven G, Peterse HL, Crommelin MA, Rutgers EJ, van de Velde CJ, et al. Local recurrence after breast conservation therapy for early stage breast carcinoma: detection, treatment, and outcome in 266 patients. Dutch Study Group on Local Recurrence after Breast Conservation (BORST). Cancer 1999;85:437-446.

22. Fowble B, Solin LJ, Schultz DJ, Rubenstein J, Goodman RL. Breast recurrence following conservative surgery and radiation: patterns of failure, prognosis, and pathologic findings from mastectomy specimens with implications for treatment. Int J Radiat Oncol Biol Phys 1990;19:833-842.

23. Dershaw DD, McCormick B, Osborne MP. Detection of local recurrence after conservative therapy for breast carcinoma. Cancer 1992;70:493-496.

24. Hassell PR, Olivotto IA, Mueller HA, Kingston GW, Basco VE. Early breast cancer: detection of recurrence after conservative surgery and radiation therapy. Radiology 1990;176:731-735.

25. Grosse A, Schreer I, Frischbier HJ, Maass H, Loening T, Bahnsen J. Results of breast conserving therapy for early breast cancer and the role of mammographic follow-up. Int J Radiat Oncol Biol Phys 1997;38:761-767.

26. Stomper PC, Recht A, Berenberg AL, Jochelson MS, Harris JR. Mammographic detection of recurrent cancer in the irradiated breast. AJR Am J Roentgenol 1987;148:39-43.
27. Ciatto S, Cataliotti L, Distante V, Rontini M, Muraca MG. Diagnostic features of 225 consecutive cases of cancer recurrence in the conserved breast. Breast 1997;6:367-370.

28. Ashkanani F, Sarkar T, Needham G, Coldwells A, Ah-See AK, Gilbert FJ, et al. What is achieved by mammographic surveillance after breast conservation treatment for breast cancer? Am J Surg 2001;182:207-210.

29. Robinson E, Rennert G, Bar-Deroma R, Dori DL, Neugut Al. The pattern of diagnosis of a second primary tumor in the breast. Breast Cancer Res Treat 1993;25:211-215.

30. Loong S, Wilkins M, Bliss JM, Davidson J, Ebbs SR, Regan J, et al. The effectiveness of the routine clinic visit in the follow-up of breast cancer patients: analysis of a defined patient cohort. Clin Oncol ( $R$ Coll Radiol) 1998;10:103-106.

31. Cawson J, Billson V, Russell I. Mammographic follow up: a vital component of breast cancer management. Aust N Z J Surg 1993;63:551-553.

32. Orel SG, Troupin RH, Patterson EA, Fowble BL. Breast cancer recurrence after lumpectomy and irradiation: role of mammography in detection. Radiology 1992;183:201-206.

33. Joseph E, Hyacinthe M, Lyman GH, Busch C, Demps L, Reintgen DS, et al. Evaluation of an intensive strategy for follow-up and surveillance of primary breast cancer. Ann Surg Oncol 1998;5:522-528.

34. Churn M, Kelly V. Outpatient follow-up after treatment for early breast cancer: updated results after 5 years. Clin Oncol (R Coll Radiol) 2001;13:187-194.

35. van der Sangen MJ, van de Poll-Franse LV, Roumen RM, Rutten HJ, Coebergh JW, Vreugdenhil G, et al. The prognosis of patients with local recurrence more than five years after breast conservation therapy for invasive breast carcinoma. Eur J Surg Oncol 2006;32:34-38.

36. Sardi A, Eckholdt G, McKinnon WM, Bolton JS. The significance of mammographic findings after breast-conserving therapy for carcinoma of the breast. Surg Gynecol Obstet 1991;173:309-312.

37. de la Rochefordiere A, Mouret-Fourme E, Asselain B, Scholl SM, Campana F, Broet $P$, et al. Metachronous contralateral breast cancer as first event of relapse. Int J Radiat Oncol Biol Phys 1996;36:615 621.

38. Lu W, Schaapveld M, Jansen L, Bagherzadegan E, Sahinovic MM, Baas $P C$, et al. The value of surveillance mammography of the contralateral breast in patients with a history of breast cancer. Eur J Cancer 2009;45:3000-3007.

39. Houssami N, Abraham LA, Miglioretti DL, Sickles EA, Kerlikowske K, Buist DS, et al. Accuracy and outcomes of screening mammography in women with a personal history of early-stage breast cancer. JAMA 2011;305:790-799.

40. Houssami N, Abraham LA, Kerlikowske K, Buist DS, Irwig L, Lee J, et al. Risk factors for second screen-detected or interval breast cancers in women with a personal history of breast cancer participating 
in mammography screening. Cancer Epidemiol Biomarkers Prev 2013;22:946-961.

41. Montgomery DA, Krupa K, Cooke TG. Follow-up in breast cancer: does routine clinical examination improve outcome? A systematic review of the literature. Br J Cancer 2007;97:1632-1641.

42. Grunfeld E, Noorani H, McGahan L, Paszat L, Coyle D, van Walraven $C$, et al. Surveillance mammography after treatment of primary breast cancer: a systematic review. Breast 2002;11:228-235.

43. Houssami N, Hunter K, Zackrisson S. Overview of tomosynthesis (3D mammography) for breast cancer screening. Breast Cancer Manag 2017:6:9-16.

44. Cho N, Han W, Han BK, Bae MS, Ko ES, Nam SJ, et al. Breast cancer screening with mammography plus ultrasonography or magnetic tesonance imaging in women 50 years or younger at diagnosis and treated with breast conservation therapy. JAMA Oncol 2017;3:1495-1502.

45. Senkus E, Kyriakides S, Ohno S, Penault-Llorca F, Poortmans P, Rutgers $E$, et al. Primary breast cancer: ESMO Clinical Practice Guidelines for diagnosis, treatment and follow-up. Ann Oncol 2015;26 Suppl 5:v8-v30.

46. Melnikow J, Fenton JJ, Whitlock EP, Miglioretti DL, Weyrich MS, Thompson JH, et al. Supplemental screening for breast cancer in women with dense breasts: a systematic review for the U.S. Preventive Services Task Force. Ann Intern Med 2016;164:268-278.

47. Tagliafico AS, Calabrese M, Mariscotti G, Durando M, Tosto S, Monetti $F$, et al. Adjunct screening with tomosynthesis or ultrasound in women with mammography-negative dense breasts: interim report of a prospective comparative trial. J Clin Oncol 2016 Mar 9 [Epub]. https://doi.org/10.1200/JC0.2015.63.4147.

48. Berg WA, Zhang Z, Lehrer D, Jong RA, Pisano ED, Barr RG, et al. Detection of breast cancer with addition of annual screening ultrasound or a single screening MRI to mammography in women with elevated breast cancer risk. JAMA 2012;307:1394-1404.

49. Suh YJ, Kim MJ, Kim EK, Moon HJ, Kim SI, Park BW. Value of ultrasound for postoperative surveillance of asian patients with history of breast cancer surgery: a single-center study. Ann Surg Oncol 2013;20:3461-3468.

50. Chinese Anti-Cancer Association Breast Cancer Committee. Chinese Anti-Cancer Association: breast cancer diagnosis and treatment guideline and standards, version 2017. China Oncol 2017;27:695760.

51. National Institute for Health and Care Excellence. Review of Clinical Guideline (CG80) - Breast cancer (early and locally advanced): diagnosis and treatment. London: National Insitute for Health and Care Excellence, 2012.

52. Moy L, Newell MS, Mahoney MC, Bailey L, Barke LD, Carkaci S, et al. ACR Appropriateness Criteria stage I breast cancer: initial workup and surveillance for local recurrence and distant metastases in asymptomatic women. J Am Coll Radiol 2014;11(12 Pt A):1160-1168.
53. Kim HJ, Kwak JY, Choi JW, Bae JH, Shin KM, Lee HJ, et al. Impact of US surveillance on detection of clinically occult locoregional recurrence after mastectomy for breast cancer. Ann Surg Oncol 2010;17:2670-2676.

54. Kim SJ, Moon WK, Cho N, Chang JM. The detection of recurrent breast cancer in patients with a history of breast cancer surgery: comparison of clinical breast examination, mammography and ultrasonography. Acta Radiol 2011;52:15-20.

55. Lee JH, Kim EK, Oh JY, Kwon HC, Kim SH, Kim DC, et al. US screening for detection of nonpalpable locoregional recurrence after mastectomy. Eur J Radiol 2013;82:485-489.

56. Song SE, Cho N, Chang JM, Chu AJ, Yi A, Moon WK. Diagnostic performances of supplemental breast ultrasound screening in women with personal history of breast cancer. Acta Radiol 2018;59:533-539.

57. Kolb TM, Lichy J, Newhouse JH. Comparison of the performance of screening mammography, physical examination, and breast US and evaluation of factors that influence them: an analysis of 27,825 patient evaluations. Radiology 2002;225:165-175.

58. Phi XA, Houssami N, Obdeijn IM, Warner E, Sardanelli F, Leach MO, et al. Magnetic resonance imaging improves breast screening sensitivity in BRCA mutation carriers age $\geq 50$ years: evidence from an individual patient data meta-analysis. J Clin Oncol 2015;33:349-356.

59. Elmore L, Margenthaler JA. Breast MRI surveillance in women with prior curative-intent therapy for breast cancer. J Surg Res 2010;163:58-62.

60. Brennan S, Liberman L, Dershaw DD, Morris E. Breast MRI screening of women with a personal history of breast cancer. AJR Am J Roentgenol 2010;195:510-516.

61. Schacht DV, Yamaguchi K, Lai J, Kulkarni K, Sennett CA, Abe H. Importance of a personal history of breast cancer as a risk factor for the development of subsequent breast cancer: results from screening breast MRI. AJR Am J Roentgenol 2014;202:289-292.

62. Gweon HM, Cho N, Han W, Yi A, Moon HG, Noh DY, et al. Breast MR imaging screening in women with a history of breast conservation therapy. Radiology 2014;272:366-373.

63. Giess CS, Poole PS, Chikarmane SA, Sippo DA, Birdwell RL. Screening breast MRI in patients previously treated for breast cancer: diagnostic yield for cancer and abnormal interpretation rate. Acad Radiol 2015;22:1331-1337.

64. Weinstock C, Campassi C, Goloubeva O, Wooten K, Kesmodel $S$, Bellevance $E$, et al. Breast magnetic resonance imaging (MRI) surveillance in breast cancer survivors. Springerplus 2015;4:459.

65. Destounis S, Arieno A, Morgan R. Personal history of premenopausal breast cancer as a risk factor for referral to screening breast MRI. Acad Radiol 2016;23:353-357.

66. Lehman CD, Lee JM, DeMartini WB, Hippe DS, Rendi MH, Kalish G, et al. Screening MRI in women with a personal history of breast cancer. J Natl Cancer Inst 2016;108:djv349. 